\title{
Detection of Frequently Used Pesticides in Apple Orchard Soil in China by High Resolution Mass Spectrometry
}

\author{
Rongguang Shi ${ }^{1}$, Li Yuan ${ }^{2}$, Mingli Chen ${ }^{2}$, Xiangqun Zheng ${ }^{1}$, Xiaowei Liu ${ }^{1}$, \\ Yujie Zhao', Aifeng Liu ${ }^{3}$, Jiaojiao Jia ${ }^{3}$, Mengmeng $\mathrm{Xu}^{3}$, Zongshan Zhao ${ }^{3,4 *}$ \\ ${ }^{1}$ Key Laboratory for Environmental Factors Control of Agro-Product Quality Safety, Agro-Environmental \\ Protection Institute, Ministry of Agriculture, Tianjin, P.R. China \\ ${ }^{2}$ Research Center for Analytical Sciences, College of Sciences, Northeastern University, Shenyang, P.R. China \\ ${ }^{3}$ CAS Key Laboratory of Biobased Materials, Qingdao Institute of Bioenergy and Bioprocess Technology, \\ Chinese Academy of Sciences, Qingdao, P.R. China \\ ${ }^{4}$ College of Environmental Science and Engineering, Qingdao University, Qingdao 266071, China
}

Received: 17 January 2019

Accepted: 14 April 2019

\begin{abstract}
In this study, 10 frequently used pesticides in apple orchards from the major apple production area of China were identified through 150 questionnaires. Based on Orbitrap high-resolution mass spectrometry, a method for detecting these pesticides in soils was developed. Typically, these compounds can be extracted from dry soil samples using dichloromethane: acetone (2:1, v:v) and purified by dispersive solid-phase extraction (PSA and C18). The qualitative and quantitative analyses can be undertaken by monitoring the MS1 precursor ions under full scan mode within a mass error of $<5 \mathrm{ppm}$ (resolution 120000). The recoveries ranged from $68.4 \%$ to $102.4 \%$ ( $\mathrm{SD}<10.5 \%$ ), the matrix effects induced signal fluctuation was less than $10 \%$, and the intra- and inter-day precisions were all below $5 \%$. For 14 surface soil samples randomly collected from an apple orchard in China, most pesticides presented the highest detection frequencies (100\%), with imidacloprid and tebuconazole showing the highest residue levels (4.1-39.1 and 9.8-350.2 ng/g dry weight, respectively). Compared with previous methods for analyzing individual or several pesticides, the proposed method represents a promising means of investigating these frequently used pesticide residues in apple orchards in China.
\end{abstract}

Keywords: pesticides, apple orchard, questionnaire, high resolution mass spectrometry, soil 


\section{Introduction}

According to information from the Apple IPM Information Network of China (http://www.apple-ipm. cn/yjk/list.asp), 16 plant diseases and insect pests are presented with their recommended pesticides, including tebuconazole, difenoconazole, pyridaben, carbendazim, chlorpyrifos, chlorbenzuron, acetamiprid, iprodione, flusilazole, and cyhalothrin. More than 50 pesticides have been used in the major apple production zones in China to control plant diseases and insect pests [1]. High amounts of pesticide use can lead to higher residue in apples and associated soils, which is closely associated with health and ecotoxicological risks [2]. For example, high levels of difenoconazole residue have been detected in apples and the corresponding soils (0.002-0.052 and $0.002-0.298 \mathrm{mg} / \mathrm{kg}$, respectively) [3]. Meanwhile, pesticide use in apple orchards could also affect nearby surface runoff, especially for mountain streams [4].

Small-scale decentralized farms are the main production units in Chinese apple production areas, such as in Shaanxi, Gansu, Henan and Shandong provinces. To protect apple trees from the threat of pests and weeds, large amounts of pesticides have been widely used every year. It should be noted that pesticide use is in a disordered state because most Chinese fruit growers know little about pesticides, pests and weeds [5]. Farmers are mainly concerned about controlling pests and weeds, rather than usage amounts and ecological risks. To date, only scarce statistics on pesticide used in apple orchards have been reported by the authorities in China. In this study, a series of national key research and development programmes containing the status of pesticides used in apple orchards have been proposed and executed in China since 2016, specifically addressing the soil pesticide residues and the associated ecological risks.

Based on HPLC-UV, HPLC-MS, GC-MS and FTIR, many methods have been developed to detect the pesticide residues in soils [6-9]. The limits of detection (LODs) and limit of quantification (LOQs) of these methods were commonly at ppb levels (ng/g), which were sensitive and effective for analysing pesticide residues, such as acetamiprid, tebuconazole and difenoconazole [3, 10-13]. Generally, several kinds of pesticides, such as organophosphorus pesticides [14], organochlorine pesticides [15] and pyrethroids [16], were involved in the processes. However, few methods have been reported for analysing pesticides frequently used in apple orchards due to the knowledge gap on the species and amounts of pesticides [17].

In this paper, 150 questionnaires on pesticide use in apple orchards from major apple production areas in China were collected and summarized. Then a method based on ultra-high-performance liquid chromatography Orbitrap-high resolution mass spectrometry (UHPLC-Orbitrap-HRMS) was developed for analysing the most frequently used pesticides.
The LODs, LOQs, recovery, matrix effects, accuracy and precision of the method have been studied. The validity has been evaluated by analysing 14 soil samples randomly collected from an apple orchard in Changwu County, Shaanxi Province.

\section{Material and Methods}

\section{Chemicals and Reagents}

Methanol, acetone, dichloromethane (DCM), ethyl acetate and acetonitrile were all purchased from Merck (Darmstadt, Germany) and Fisher Scientific (Trinidad, UK). All chemicals were of chromatographic reagent grade. Formic acid was obtained from Dikma Technologies (USA). Analytical-grade standards (purities $>98 \%$ ), carbendazim, imidacloprid, acetamiprid, triadimenol, triadimefon, tebuconazole, chlorbenzuron, difenoconazole, chlorpyrifos, buprofezin, and pyridaben were purchased from Dr. Ehrenstorfer (Augsburg, Germany) and Sigma-Aldrich (Steinheim, Germany). Individual chemical stock solutions $(2 \mathrm{mg} / \mathrm{mL})$ were prepared in HPLC-grade methanol and stored in the dark at $-20^{\circ} \mathrm{C}$. Anhydrous sodium sulfate $\left(\mathrm{Na}_{2} \mathrm{SO}_{4}\right)$, primary-secondary amine (PSA) bonded silica bulk, octadecylsilane (LC-C18, 40-63 $\mu \mathrm{m}$ ) and nylon syringe filters $(0.22 \mu \mathrm{m})$ were obtained from Shanghai Anpel Scientific Instrument Co., Ltd. (Shanghai, China). Ultra-pure water was obtained from a Milli-Q system (Bedford, MA, USA).

\section{Sample Collection}

All of the 14 surface soil samples $(0-20 \mathrm{~cm}$ depth $)$ were collected from an apple orchard $(350 \times 150 \mathrm{~m})$ in Changwu, Shaanxi Province, China in August 2017. At this time, tebuconazole, pyridaben and chlorbenzuron were often used to prevent trunk canker, European red mite and tan disease. Fourteen soil samples were randomly collected from the orchard and then quickly transported to the lab, freeze-dried, ground, sieved (100 mesh) and stored in a refrigerator at $-20^{\circ} \mathrm{C}$ until analysis.

The physical-chemical properties of the soil samples are shown in Table 1. The environment behaviours of the organic chemicals in soil are often influenced by organic matter and $\mathrm{pH}[18,19]$. The mean $\mathrm{pH}$ values $(7.94 \pm 0.16)$ and organic matters $(12.6 \pm 2.0 \mathrm{~g} / \mathrm{kg})$ of the soil samples (S1-S14) are similar to those of the main apple-producing areas of China $(\mathrm{pH}>7.5$, organic matter $>10.0 \mathrm{~g} / \mathrm{kg}$ ) [20, 21]. A blank soil sample (S0) (pH of 8.17 and organic matters of $11.2 \mathrm{~g} / \mathrm{kg}$ ) is chosen as the representative sample for method validation.

\section{Sample Preparation}

Before analysis, $5 \mathrm{~g}$ homogenized samples were weighed in a $50-\mathrm{mL}$ glass centrifuge tube and spiked 
Table 1. Physical-chemical properties of the soils.

\begin{tabular}{|c|c|c|c|c|c|c|c|c|c|c|c|c|c|c|c|}
\hline Parameter & S0 & S1 & S2 & S3 & S4 & S5 & S6 & S7 & S8 & S9 & S10 & S11 & S12 & S13 & S14 \\
\hline $\mathrm{pH}$ & 8.17 & 8.01 & 7.69 & 7.85 & 7.74 & 8.22 & 8.13 & 8.05 & 7.85 & 7.95 & 7.80 & 7.81 & 7.92 & 7.99 & 8.11 \\
\hline Organic matter $(\mathrm{g} / \mathrm{kg})$ & 11.2 & 10.6 & 12.5 & 11.4 & 14.3 & 13.6 & 10.4 & 12.4 & 10.1 & 9.9 & 12.4 & 13.9 & 15.8 & 16.1 & 12.3 \\
\hline
\end{tabular}

at three different levels for 11 pesticides. The soil samples were mixed uniformly after the addition of $3 \mathrm{~g}$ $\mathrm{Na}_{2} \mathrm{SO}_{4}$. Afterward, the mixture was mixed with $30 \mathrm{~mL}$ $\mathrm{DCM} /$ acetone $(2 / 1, \mathrm{v} / \mathrm{v}$, containing $0.1 \%$ formic acid). Then the mixture was vortexed vigorously for $5 \mathrm{~min}$ and ultrasonically extracted for $20 \mathrm{~min}$. After centrifugation at $3000 \mathrm{rpm}$ for $5 \mathrm{~min}$, the supernatant was collected. The extraction processes were repeated another two times. The extracts were combined, rotary evaporated and re-dissolved in $1 \mathrm{~mL}$ of methanol. PSA $(100 \mathrm{mg})$ and LC-C18 (50 mg) were weighed into the bottle, mixed with the solvent and vortexed vigorously for $3 \mathrm{~min}$ to purify the extracts. The supernatant was filtered through a $0.22-\mu \mathrm{m}$ nylon filter and diluted with water $(20 \%, \mathrm{v} / \mathrm{v})$ before analysis using UHPLC-Orbitrap-HRMS.

\section{Instrument Conditions}

Sample analysis was performed by a Thermo Ultimate 3000 UHPLC coupled with an Orbitrap Fusion Tribrid mass spectrometer (Thermo Fisher Scientific, USA) and equipped with an ACQUITY UPLC BEH C18 column $(100 \times 2.1 \mathrm{~mm}, 1.7 \mu \mathrm{m}$, Waters $)$. The mobile phase consists of $0.1 \%$ formic acid in acetonitrile (A) and water $(\mathrm{B})$ at a flow rate of $0.3 \mathrm{~mL} / \mathrm{min}$. The initial gradient was set to $10 \% \mathrm{~A}$ and held for $3 \mathrm{~min}$ before starting a linear gradient that increased to $100 \% \mathrm{~A}$ in $17 \mathrm{~min}$ and held for $2 \mathrm{~min}$. Then the gradient returned to the initial conditions for $2 \mathrm{~min}$. The column temperature was set to $30^{\circ} \mathrm{C}$.

Electrospray ionization was conducted in the positive ionization mode. The recommended values were used in the full scan acquisition from $\mathrm{m} / \mathrm{z} 100$ to 800 without further optimization. Collision-induced dissociation (CID) in Orbitrap Fusion HRMS was applied to collect the MS2 pesticide information. The parameters used for the mass spectrometer were as follows: spray voltage, $3500 \mathrm{~V}$; sweep gas flow rate, 1 respective arbitrary units; sheath gas flow rate, 30 respective arbitrary units; aux gas flow rate, 8 respective arbitrary units; ion transfer tube temperature, $350^{\circ} \mathrm{C}$; vaporizer temperature, $200^{\circ} \mathrm{C}$; MS1 detector, Orbitrap; MS1 resolution, 120,000; MS1 scan range, 100-800; MS1 maximum injection time, $100 \mathrm{~ms}$; MS1 automated gain control (AGC) target, 100,000; S-lens RF level, $60 \mathrm{~V}$; MS2 CID collision energy, 30\%; MS2 detector, Orbitrap; MS2 resolution, 30,000; MS2 AGC target, 50,000; MS2 maximum injection time, $100 \mathrm{~ms}$; and MS2 start mass, 50. Xcalibur Qual and Quan Browser software were used for the qualitative and quantitative analyses.

\section{Method Validation}

The linearity, LODs, LOQs, recovery, matrix effects and precision were evaluated for this method. Serial standard pesticide dilutions $(0.5,1,2,5,10,20,50,100$, and $500 \mathrm{ng} / \mathrm{mL}$ ) with methanol/water (80:20, v:v) were prepared using a standard stock solution $(2 \mathrm{mg} / \mathrm{mL}$ in methanol) mixture of the 11 pesticides. Correspondingly, matrix-matched standard solutions were prepared (50, $500 \mathrm{ng} / \mathrm{mL}$ ) by mixing the corresponding standards with concentrated sample extracts. The matrix-induced signal suppression or enhancement was determined by comparison with the signals of pure standards [22]. The LODs and LOQs were established based on the lowest concentration with a signal-to-noise ratio $(\mathrm{S} / \mathrm{N})$ of $3: 1$ and 10:1. The recovery of soil samples was conducted to evaluate the accuracy, precision and feasibility of the method. The intra-day precision (repeatability) was performed at the same two concentration levels as the recovery studies. The intermediate precision (interday precision) was studied by spiking blank samples at 10 and $100 \mathrm{ng} / \mathrm{g}$ in different days. Three replicates of the spiked samples at three levels $(10,100$ and $500 \mathrm{ng} / \mathrm{g} \mathrm{dw}$ of each pesticide) were prepared to evaluate the recoveries.

\section{Results and Discussion}

\section{Questionnaire Survey Results}

The recommended pesticides (60 kinds) for pest and weed prevention in a Chinese apple orchard were involved in the self-designed questionnaire, which was used for investigating the type, quantity and time of application of pesticides. The questionnaires were focused on the local farmers and the agricultural machine stations in Shaanxi Province (120 questionnaires) and Shanxi Province (30 questionnaires). The used frequencies (UFs) of 60 pesticides were counted by the 150 completed questionnaires (Table 2). The results showed that there were 10 pesticides presenting higher UFs ( $>85 \%$ ) among all of the 60 inquisitional pesticides. These pesticides were carbendazim (UF $=100.0 \%$ ), tebuconazole (UF $=100.0 \%)$ chlorbenzuron $(\mathrm{UF}=91.3 \%)$, chlorpyrifos $(\mathrm{UF}=92.0 \%)$, buprofezin $(\mathrm{UF}=90.0 \%)$, difenoconazole $(\mathrm{UF}=88.7 \%)$, triadimefon (UF $=89.3 \%$, metabolite triadimenol), acetamiprid $(\mathrm{UF}=88.7 \%)$, imidacloprid $(\mathrm{UF}=87.3 \%)$ and pyridaben (UF $=86.0 \%$ ). To a certain extent, the residues of these 
Table 2. Use frequencies of the pesticides from the questionnaires.

\begin{tabular}{|c|c|c|c|c|}
\hline & Docticides & $\begin{array}{l}\text { Shaanxi } \\
(120)\end{array}$ & $\begin{array}{c}\text { Shanxi } \\
(30)\end{array}$ & $\begin{array}{l}\text { Average } \\
\text { frequen- }\end{array}$ \\
\hline & resticiates & $\begin{array}{c}\text { Frequency } \\
(\%)\end{array}$ & $\begin{array}{c}\text { Frequency } \\
(\%)\end{array}$ & $\begin{array}{c}\text { cy } \\
(\%)\end{array}$ \\
\hline 1 & Carbendazim & 100.0 & 100.0 & 100.0 \\
\hline 2 & Tebuconazole & 100.0 & 100.0 & 100.0 \\
\hline 3 & Chlorbenzuron & 91.7 & 90.0 & 91.3 \\
\hline 4 & Chlorpyrifos & 90.0 & 100.0 & 92.0 \\
\hline 5 & Buprofezin & 90.0 & 90.0 & 90.0 \\
\hline 6 & Difenoconazole & 89.2 & 86.7 & 88.7 \\
\hline 7 & Triadimefon & 88.3 & 93.3 & 89.3 \\
\hline 8 & Acetamiprid & 88.3 & 90.0 & 88.7 \\
\hline 9 & Imidacloprid & 88.3 & 83.3 & 87.3 \\
\hline 10 & Pyridaben & 85.0 & 90.0 & 86.0 \\
\hline 11 & Cyhalothrin & 83.3 & 76.7 & 82.0 \\
\hline 12 & Thiophanate-mythyl & 83.3 & 80.0 & 82.7 \\
\hline 13 & Polyoxins & 75.0 & 76.7 & 75.3 \\
\hline 14 & $\begin{array}{l}\text { Ammonium } \\
\text { glyphosate }\end{array}$ & 75.0 & 66.7 & 73.3 \\
\hline 15 & Mancozeb & 70.8 & 63.3 & 69.3 \\
\hline 16 & Bordeaux mixture & 70.0 & 63.3 & 68.7 \\
\hline 17 & Atrazine & 61.7 & 60.0 & 61.3 \\
\hline 18 & Pymetrozine & 54.2 & 60.0 & 55.3 \\
\hline 19 & Copper sulfate & 54.2 & 53.3 & 54.0 \\
\hline 20 & Pyraclostrobin & 48.3 & 40.0 & 46.7 \\
\hline 21 & Chlorantraniliprole & 30.0 & 23.3 & 28.7 \\
\hline 22 & Carbosulfan & 15.0 & 10.0 & 14.0 \\
\hline 23 & $\begin{array}{l}\text { Tetracycline/ } \\
\text { Oxytetracycline/ } \\
\text { Streptomycin }\end{array}$ & 8.3 & 6.7 & 8.0 \\
\hline 24 & Thiram•asomate & 5.0 & 10.0 & 6.0 \\
\hline 25 & Chlorothalonil & 5.0 & 6.7 & 5.3 \\
\hline 26 & Benomyl & 3.3 & 6.7 & 4.0 \\
\hline 27 & Amobam & 3.3 & 6.7 & 4.0 \\
\hline 28 & Nitenpyram & 0 & 0 & 0 \\
\hline 29 & Dinotefuran & 0 & 0 & \\
\hline
\end{tabular}

\begin{tabular}{|c|c|c|c|c|}
\hline 30 & Clothianidin & 0 & 0 & 0 \\
\hline 31 & Sulfoxaflor & 0 & 0 & 0 \\
\hline 32 & Thiamethoxam & 0 & 0 & 0 \\
\hline 33 & Dichlorvos * & 0 & 0 & 0 \\
\hline 34 & Isocarbophos * & 0 & 0 & 0 \\
\hline 35 & Triazophos & 0 & 0 & 0 \\
\hline 36 & Profenofos * & 0 & 0 & 0 \\
\hline 37 & Diflubenzuron & 0 & 3.3 & 0.7 \\
\hline 38 & Phoxim * & 0 & 0 & 0 \\
\hline 39 & Acephate * & 0 & 0 & 0 \\
\hline 40 & Bifenthrin & 0 & 0 & 0 \\
\hline 41 & Dipterex * & 0 & 0 & 0 \\
\hline 42 & $\begin{array}{c}\text { Dimethoate/ometh- } \\
\text { oate } *\end{array}$ & 0 & 0 & 0 \\
\hline 43 & Ethofenprox & 0.8 & 0 & 0.7 \\
\hline 44 & Thiprole & 0 & 0 & 0 \\
\hline 45 & Monosultap * & 0 & 0 & 0 \\
\hline 46 & Dimehypo * & 0 & 0 & 0 \\
\hline 47 & Methomyl * & 0 & 0 & 0 \\
\hline 48 & Indoxacarb & 0 & 0 & 0 \\
\hline 49 & $\begin{array}{c}\text { Propineb• Tebuco- } \\
\text { nazole }\end{array}$ & 0 & 0 & 0 \\
\hline 50 & Vinclozolin & 0 & 0 & 0 \\
\hline 51 & Fosetyl-aluminum & 0 & 3.3 & 0.7 \\
\hline 52 & Metalaxyl & 0 & 0 & 0 \\
\hline 53 & Pretilachlor & 1.7 & 0 & 1.3 \\
\hline 54 & Butachlor & 0 & 0 & 0 \\
\hline 55 & Acetochlor & 0 & 3.3 & 0.7 \\
\hline 56 & Paraquat * & 0 & 0 & 0 \\
\hline 57 & Quizalofop-p-ethyl & 0 & 0 & 0 \\
\hline 58 & Oxyfluorfen & 0 & 0 & 0 \\
\hline 59 & Thiram & 0 & 0 & 0 \\
\hline 60 & Asomate * & 0 & 0 & 0 \\
\hline
\end{tabular}

*, banned pesticides in China

10 compounds and triadimenol might represent the entire usage situation of Chinese pesticides. In this study, a method for monitoring these 11 pesticides based on Orbitrap-HRMS was developed to enable large-scale soil residue investigations in apple orchards.

\section{Optimizing UHPLC-Orbitrap-HRMS Conditions}

Benefiting from the high resolution of UHPLCOrbitrap-HRMS (120,000), the extracted mass ranges could be strictly limited according to the theoretical values with a mass error of $<5 \mathrm{ppm}$. The sample interferences were always excluded by higher 


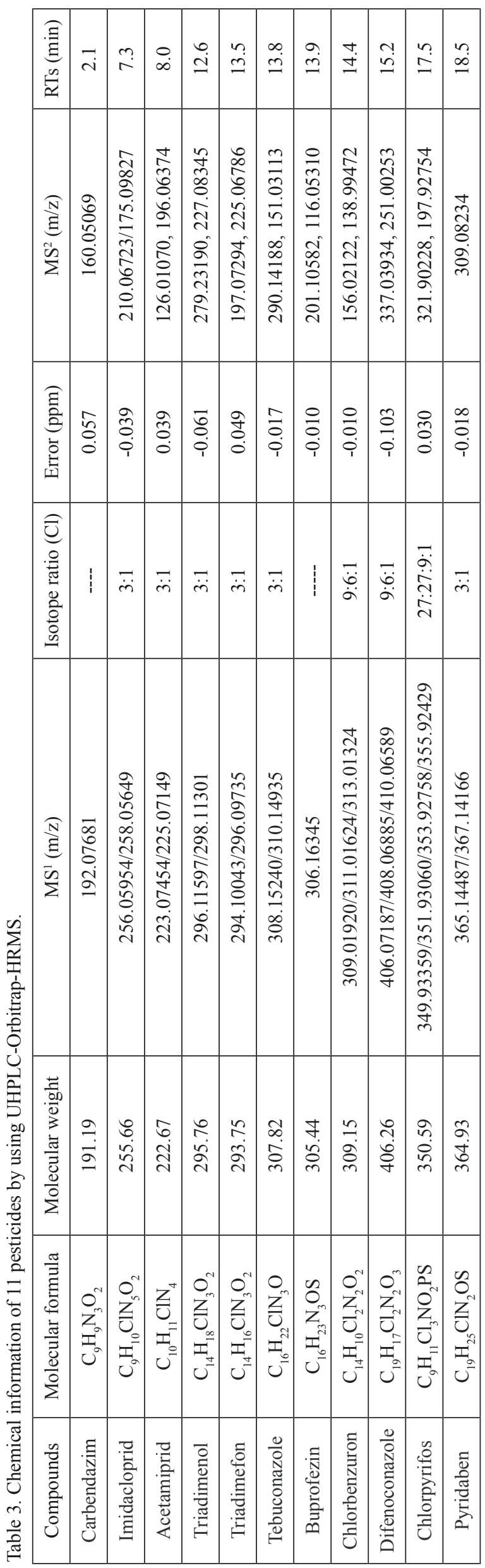

resolutions. In this study, the recommended condition for UHPLC-Orbitrap-HRMS was used directly, and both full scan (MS1) and fragmentation (MS2) data were obtained at the same time. MS1 data of the 11 pesticides were used for identification and quantitation by comparing the mass information and retention time with that of pure standards (Table 3). More information, including accurate MS1 m/z values, isotopic ratios and MS2 characteristics, could be given by one injection. The identification of the target chemicals by UHPLCOrbitrap-HRMS displays more finger information than HPLC-MS/MS.

For optimizing UHPLC conditions, mobile phase composition, flow rate and solvent composition were evaluated. The mobile phase containing acetonitrile and water was more likely to elute the pesticides from the column than that consisting of methanol and water. Additionally, the addition of $0.1 \%$ formic acid is in favour of the positive ionization of pesticides and their separation on column, which is in accordance with the results in the literature [23, 24]. An ACQUITY UPLC BEH C18 $(2.1 \times 100 \mathrm{~mm}, 1.7 \mu \mathrm{m}$, Waters $)$ was used for optimization of the elution conditions. When the flow rate increased from $0.2 \mathrm{~mL} / \mathrm{min}$ to $0.4 \mathrm{~mL} / \mathrm{min}$, the tailing peaks decreased, but peak kurtosis was not improved, especially for polar chemicals of carbendazim, imidacloprid and acetamiprid. This finding can be attributed to the higher elution capacity of a substance in a solvent than that of the mobile phase. The addition of a certain amount of water to the standard solution could solve this problem. However, high levels of water (e.g., 50\%) reduce pesticide solubility. Finally, a solvent containing $20 \%$ water in methanol is used for dissolving the pesticides and as the sample solvent. Finally, the solvent of methanol/water $(80 / 20, v / v)$ and the mobile phase of acetonitrile and water (containing $0.1 \%$ formic acid) at a flow rate of $0.3 \mathrm{~mL} / \mathrm{min}$ were applied for separating these 11 pesticides in $25 \mathrm{~min}$ with a rare peak overlap (Fig. 1).

\section{Optimizing Extraction and Clean-Up Procedures}

To obtain good recoveries, a series of organic solvents, including acetonitrile, methanol, acetone, ethyl acetate, DCM and their mixtures were tested. Both extraction efficiencies and co-extracted interferences were used as the evaluation items. The results showed that there were more interferences when using acetonitrile, methanol and acetone as the sole solvents. For DCM or ethyl acetate, this approach could lead to low extraction efficiencies for polar analytes, such as carbendazim and imidacloprid. The combination of solvents, including acetone/ethyl acetate $(2 / 3, \mathrm{v} / \mathrm{v})$, acetone/DCM $(1 / 2, \mathrm{v} / \mathrm{v})$, and DCM/ethyl acetate $(1 / 2$, $\mathrm{v} / \mathrm{v}$ ) were also tested. The extraction efficiencies using acetone/DCM (1/2) presented the best performance, with the recoveries ranging from $72.0 \%$ to $102.4 \%$ at a spiking level of $100 \mathrm{ng} / \mathrm{g} \mathrm{dw}$. The addition of $0.1 \%$ 


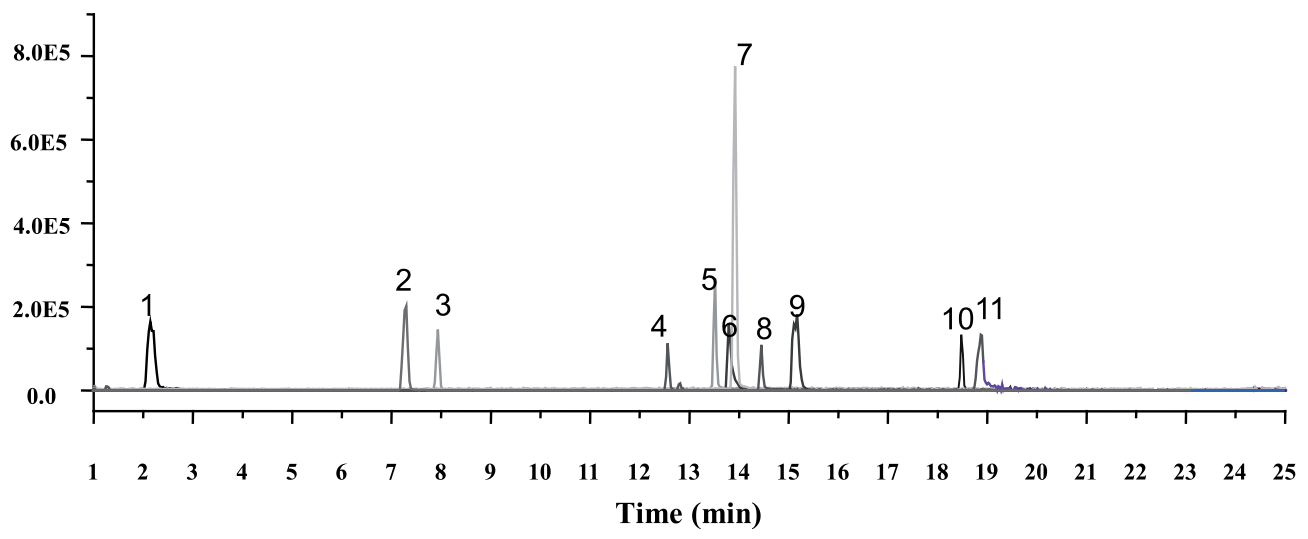

Fig. 1. HRMS chromatogram of 11 pesticides.

1, Carbendazim (10 ng/mL); 2, Imidacloprid (20 ng/mL); 3, Acetamiprid (10 ng/mL); 4, Triadimenol (50 ng/mL); 5, Triadimefon $(10 \mathrm{ng} / \mathrm{mL}) ; 6$, Tebuconazole (10 ng/mL); 7, Buprofezin (10 ng/mL); 8, Chlorbenzuron (50 ng/mL); 9, Difenoconazole $(10 \mathrm{ng} / \mathrm{mL})$; 10, Chlorpyrifos (100 ng/mL); 11, Pyridaben $(20 \mathrm{ng} / \mathrm{mL})$.

formic acid improved the method performance with the recovery efficiencies of the analytes increasing by $1-10 \%$, especially for carbendazim. Ultimately, acetone/ DCM $(1 / 2$, containing $0.1 \%$ formic acid) was chosen as the extraction solvent.

LC-C18, PSA and ENVI-Carb SPE cartridges are the commonly used clean-up materials for analysing pesticide residues, especially for eliminating pigment matters [4, 25-27]. The recoveries of pesticides (100 ng/g dw) eluted from the ENVI-Carb SPE cartridge (6 cc, $500 \mathrm{mg}$, Supelco) ranged 10-30\%. This result can be attributed to the higher absorption capacity between the carbon packing and the pesticides [28]. PSA and C18 are often used in the QuEChERS method to remove the polar matrix components by absorption or extraction $[29,30]$. Similar to that in most QuEChERS methods [31, 32], PSA (100 mg) and C18 (50 mg), which presented a better elimination performance, were chosen as the clean-up media.

\section{Analytical Performance}

Under the optimized conditions, the performance of the developed method was systematically evaluated (Table 4). Calibration curves of most pesticides were in the range of 0.5 to $500 \mathrm{ng} / \mathrm{mL}$, except triadimenol (1-500 $\mathrm{ng} / \mathrm{mL})$, chlorbenzuron $(1-500 \mathrm{ng} / \mathrm{mL})$, pyridaben $(2-500 \mathrm{ng} / \mathrm{mL})$ and chlorpyrifos $(10-500 \mathrm{ng} / \mathrm{mL})$. There was good linearity for the 11 pesticides $\left(r^{2}>0.99\right)$. The LODs $(\mathrm{S} / \mathrm{N}=3)$ ranged from 0.2 to $1.5 \mathrm{ng} / \mathrm{g} \mathrm{dw}$, and the LOQs $(\mathrm{S} / \mathrm{N}=10)$ ranged from 0.6 to $4.0 \mathrm{ng} / \mathrm{g} \mathrm{dw}$. LODs and LOQs were comparable to that of HPLCESI-MS/MS methods (1-20 ng/g) developed for food (pomegranate, coconut and wheat, etc.) residue analysis [31-34], but considerably lower than the methods based on HPLC-MS/MS, GC-ECD/MS and HPLC-UV (5-79 $\mathrm{ng} / \mathrm{g})$ for soil residue analysis [35-37].

When spiked at levels of 10,100 and $500 \mathrm{ng} / \mathrm{g} \mathrm{dw}$ in soil samples, recoveries ranged from 68.4 to $102.4 \%$, and SD values were lower than $10.5 \%$. The intra-day
RSD and inter-day RSD at levels of 10 and $100 \mathrm{ng} / \mathrm{g} \mathrm{dw}$ were $1.0-4.5 \%$ and $2.3-4.4 \%$, respectively.

The matrix effects (ME), which often induce signals enhancement or suppression in MS analysis, have been studied using the following equation:

$$
\mathrm{ME}=\frac{A_{\text {matrix }}}{A_{\text {solvent }}} \times 100 \%
$$

...where $\mathrm{A}_{\text {solvent }}$ is the detected peak area of the standard solution and $\mathrm{A}_{\text {matrix }}$ is the detected peak area of the same chemical, which is prepared in the extracted matrix of the blank sample with the same levels of standard solutions. The numerical value of $100 \%$ of ME represents no matrix effect, while lower or higher than $100 \%$ represents signal suppression or enhancement, respectively.

We evaluated the matrix effects at two spiking levels (50 and $500 \mathrm{ng} / \mathrm{mL}$ ). As shown in Table 4, the matrix effects of 11 targeted pesticides were $93.6-104.6 \%$ at $50 \mathrm{ng} / \mathrm{mL}$ and $92.4-104.2 \%$ at $500 \mathrm{ng} / \mathrm{mL}$. A signal fluctuation of less than $10 \%$ suggested that the matrix effects can be neglected in this study.

\section{Application in Real Samples}

The most commonly used method in China for applying pesticides is hydraulic pressure atomization. This approach often causes uncovered soil under trees to be exposed to pesticides [38]. To investigate the residue levels of these frequently used pesticides in apple orchards, 14 surface soil samples (S1-S14) were randomly collected and analyzed by the developed method (Table 5). Tebuconazole, carbendazim, imidacloprid, difenoconazole, chlorpyrifos, buprofezin and pyridaben presented the highest detection frequency of $100 \%$. These pesticides were followed by chlorbenzuron $(92.8 \%)$, triadimefon $(85.7 \%)$, acetamiprid (42.8\%) and triadimenol $(28.6 \%)$. Tebuconazole showed the highest 


\begin{tabular}{|c|c|c|c|c|c|c|c|c|c|c|c|c|}
\hline \multicolumn{2}{|c|}{ 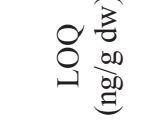 } & $\stackrel{0}{\circ}$ & $\stackrel{\circ}{i}$ & $\stackrel{0}{\circ}$ & $\ddot{n}$ & $\stackrel{?}{\longrightarrow}$ & $\stackrel{\sim}{\sim}$ & $\ddot{n}$ & $\stackrel{\infty}{0}$ & $\stackrel{\circ}{+}$ & $\stackrel{\circ}{-}$ & $\stackrel{\sim}{n}$ \\
\hline \multicolumn{2}{|c|}{ ○े } & ชี & $\stackrel{\infty}{0}$ & $\tilde{o}$ & $\stackrel{\text { Iִ }}{-}$ & $\stackrel{t}{0}$ & ?3. & $\exists$ & กֶ. & $\because$ & ?3. & $\hat{o}$ \\
\hline \multirow{2}{*}{ 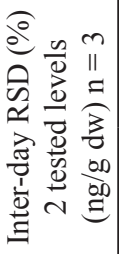 } & $\stackrel{0}{\dot{8}}$ & $\ddot{\dot{r}}$ & $\stackrel{b}{i}$ & $\ddot{n}$ & $\overrightarrow{\mathrm{i}}$ & $\underset{i}{0}$ & $\stackrel{+}{i}$ & $\stackrel{\infty}{\dot{n}}$ & $\stackrel{b}{\sim}$ & $\stackrel{+}{+}$ & $\dot{m}$ & $\hat{i}$ \\
\hline & $\stackrel{\circ}{\circ}$ & $\stackrel{\bullet}{i}$ & $\vec{m}$ & $\stackrel{\sim}{i}$ & $\underset{\sim}{\tilde{n}}$ & $\vec{m}$ & $\vec{m}$ & $\hat{i}$ & $\vec{\lambda}$ & $\stackrel{\sim}{i}$ & F & $\stackrel{m}{i}$ \\
\hline \multirow{2}{*}{ 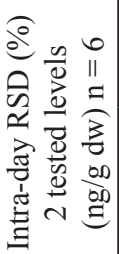 } & $\stackrel{\circ}{\stackrel{8}{\circ}}$ & $\stackrel{\leftarrow}{i}$ & $\vec{i}$ & 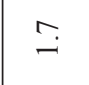 & $\stackrel{?}{+}$ & $\stackrel{\circ}{-}$ & $\stackrel{b}{\dot{m}}$ & $\stackrel{\circ}{+}$ & $\stackrel{b}{r}$ & $\hat{i}$ & $\stackrel{-}{-}$ & $\stackrel{\text { Iִ }}{-}$ \\
\hline & $\stackrel{\circ}{\ominus}$ & $\because$ & $\stackrel{\sim}{i}$ & $\stackrel{\sim}{\sim}$ & 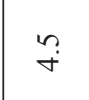 & $\vec{i}$ & $\stackrel{\infty}{i}$ & $\stackrel{\infty}{\dot{n}}$ & $\overrightarrow{\mathrm{i}}$ & $\stackrel{?}{-}$ & $\vec{i}$ & $\stackrel{\circ}{i}$ \\
\hline \multirow{2}{*}{ 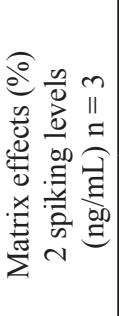 } & $\begin{array}{l}\stackrel{8}{\circ} \\
\stackrel{8}{\circ}\end{array}$ & 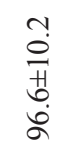 & $\begin{array}{l}n \\
0 \\
11 \\
2 \\
\hat{\alpha}\end{array}$ & 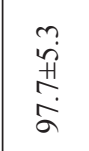 & $\begin{array}{l}\hat{0} \\
\infty \\
ث \\
\ddot{a} \\
\ddot{a}\end{array}$ & $\begin{array}{l}0 \\
\dot{0} \\
\ddot{1} \\
\infty \\
\infty\end{array}$ & $\begin{array}{l}\stackrel{a}{+} \\
+ \\
\infty \\
\stackrel{0}{0}\end{array}$ & 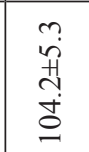 & 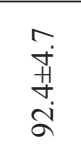 & \begin{tabular}{l}
$n$ \\
\multirow{1}{a}{} \\
\multirow{2}{a}{}
\end{tabular} & 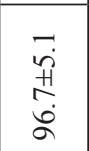 & 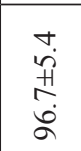 \\
\hline & $\stackrel{\circ}{\circ}$ & 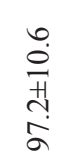 & 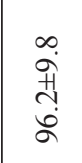 & 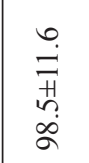 & 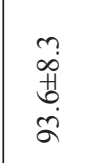 & 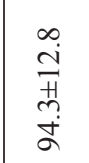 & $\begin{array}{l}n \\
\text { Oें } \\
0 \\
\dot{0} \\
0\end{array}$ & $\begin{array}{l}\hat{0} \\
\infty \\
\infty \\
\infty \\
\dot{a}\end{array}$ & 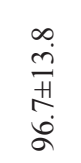 & $\begin{array}{l}\stackrel{m}{=} \\
\bar{H} \\
n \\
\infty\end{array}$ & $\begin{array}{l}\text { ì } \\
\text { सु } \\
\dot{d} \\
\dot{d}\end{array}$ & $\begin{array}{l}\text { j } \\
\text { 苦 } \\
\stackrel{0}{\circ}\end{array}$ \\
\hline \multirow{3}{*}{ 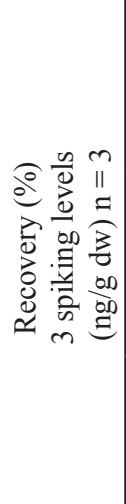 } & 官 & $\begin{array}{l}n \\
0 \\
\forall \\
\forall \\
n \\
a\end{array}$ & $\begin{array}{l}\infty \\
\tilde{D} \\
\forall \\
\dot{\forall} \\
0\end{array}$ & 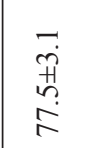 & $\begin{array}{l}\stackrel{0}{0} \\
\text { in } \\
\infty \\
\stackrel{i}{n}\end{array}$ & 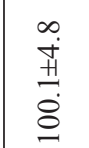 & 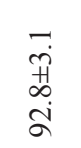 & $\begin{array}{l}\overrightarrow{0} \\
\text { से } \\
\dot{0} \\
\dot{0}\end{array}$ & 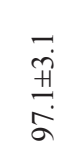 & $\begin{array}{l}\overrightarrow{0} \\
\infty \\
+ \\
\ddot{0} \\
\infty\end{array}$ & $\begin{array}{l}n \\
\tilde{H} \\
m \\
\tilde{n}\end{array}$ & $\begin{array}{l}\hat{\vec{j}} \\
\text { j } \\
\infty \\
\infty\end{array}$ \\
\hline & $\stackrel{\circ}{\circ}$ & $\begin{array}{l}\stackrel{r}{\tilde{T}} \\
\stackrel{+}{+} \\
\dot{\theta}\end{array}$ & $\begin{array}{l}\infty \\
\text { in } \\
+1 \\
0 \\
\dot{0}\end{array}$ & $\begin{array}{l}0 \\
\dot{T} \\
\infty \\
\infty \\
\dot{0}\end{array}$ & $\begin{array}{l}\stackrel{+}{N} \\
\text { i⿱艹 } \\
\stackrel{i}{i}\end{array}$ & $\begin{array}{l}\overrightarrow{\dot{H}} \\
\infty \\
\infty \\
\infty\end{array}$ & 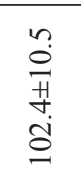 & 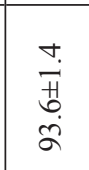 & $\begin{array}{l}\vec{T} \\
\text { मे } \\
\infty \\
\infty\end{array}$ & $\begin{array}{l}\text { तु } \\
\text { से } \\
\text { ¿ें } \\
\text { a }\end{array}$ & $\begin{array}{l}+ \\
\dot{+} \\
+ \\
\infty \\
\infty \\
\infty\end{array}$ & 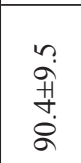 \\
\hline & $\stackrel{\circ}{\circ}$ & 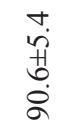 & 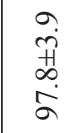 & 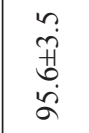 & $\begin{array}{l}\hat{D} \\
\dot{0} \\
\dot{y} \\
\dot{\infty}\end{array}$ & \begin{tabular}{l}
0 \\
$\stackrel{+}{0}$ \\
\multirow{1}{0}{} \\
$\stackrel{\infty}{\infty}$
\end{tabular} & 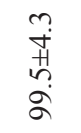 & $\begin{array}{l}0 \\
\tilde{H} \\
\tilde{n} \\
n\end{array}$ & 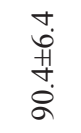 & $\begin{array}{l}\stackrel{\infty}{+} \\
\underset{+}{+} \\
\stackrel{\infty}{+}\end{array}$ & $\begin{array}{l}\text { iे } \\
\text { in } \\
\text { है }\end{array}$ & 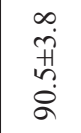 \\
\hline 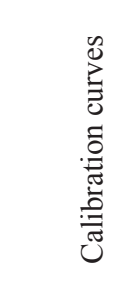 & & 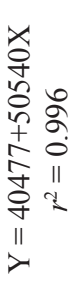 & 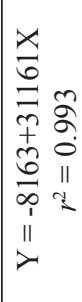 & 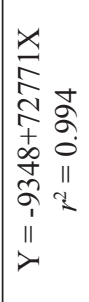 & 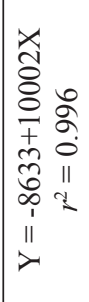 & 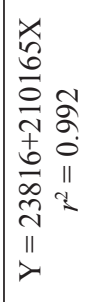 & 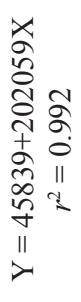 & 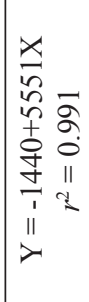 & 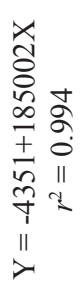 & 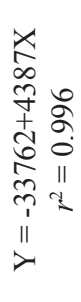 & 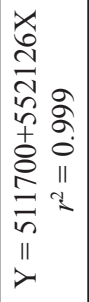 & 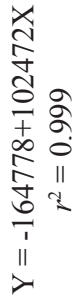 \\
\hline 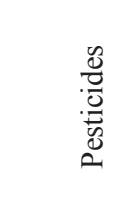 & & 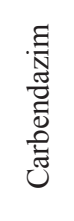 & 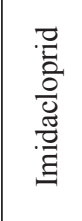 & 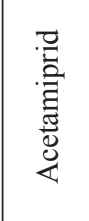 & 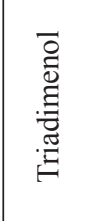 & 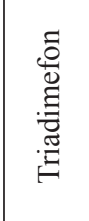 & 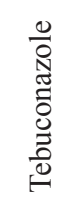 & 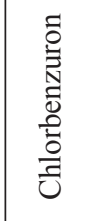 & 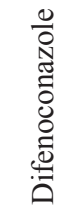 & 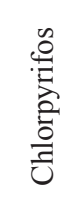 & 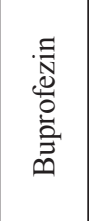 & 离 \\
\hline
\end{tabular}




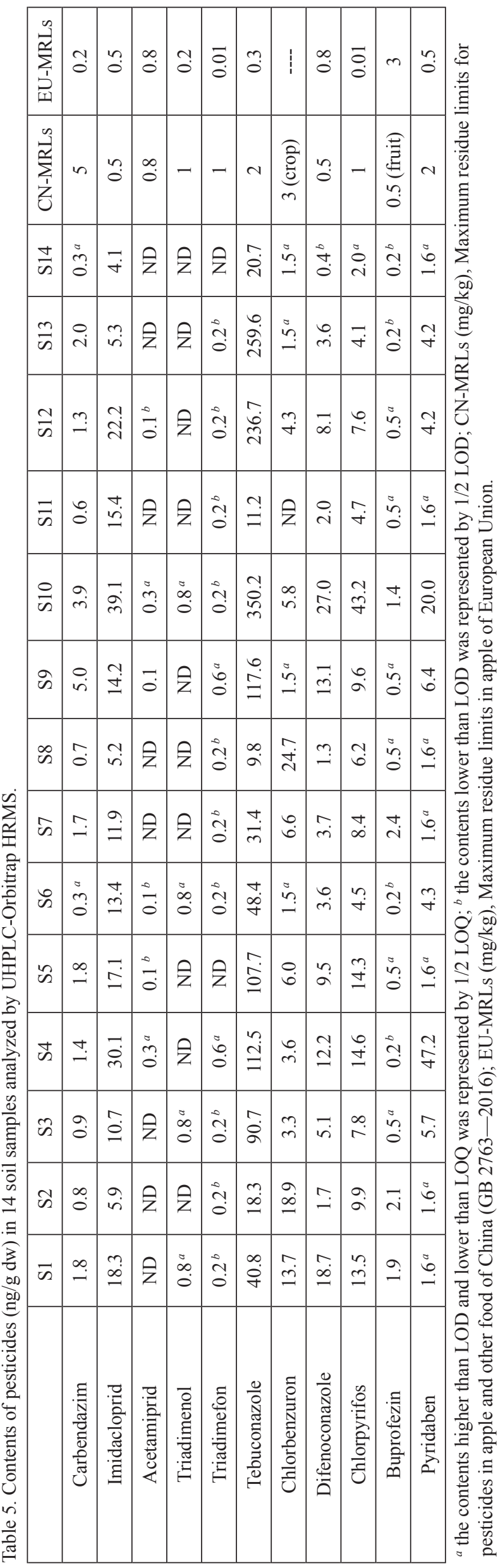

levels $(9.8-350.2 \mathrm{ng} / \mathrm{g} \mathrm{dw})$, which coincide well with its higher-use frequency. Among these detected pesticides, both imidacloprid and chlorpyrifos also presented higher levels, with contents ranging from 4.1 to 39.1 and 2.0 to $43.2 \mathrm{ng} / \mathrm{g} \mathrm{dw}$, respectively, which were slightly lower than imidacloprid in crude pollen samples (3.2-4516 ng/g) [39] and chlorpyrifos in fresh vegetable samples $(5-500 \mathrm{ng} / \mathrm{g})$ [40]. The higher contents of imidacloprid in soils could be attributed to their longer half-lives in soil ( $t_{1 / 2}>20$ days) [41]. The other 9 detected pesticides in most of the soil samples were approximately $1-20 \mathrm{ng} / \mathrm{g} \mathrm{dw}$, which is comparable to values previously reported in food samples [25, 42]. The soil pesticide contents were all below the MRLs of China $(0.5-5 \mathrm{mg} / \mathrm{kg}$ ) and the European Union $(0.01-3 \mathrm{mg} / \mathrm{kg})$, indicating their low acute toxic risks.

\section{Conclusions}

In this study, 150 questionnaires were collected to determine the most-used pesticides in apple orchards. The results showed that there were 10 highly frequently used chemicals. Based on the questionnaires, a sensitive method using UHPLC-Orbitrap-HRMS was developed for simultaneously detecting these 10 pesticides and one metabolite. Good performance in analyzing 14 soil samples randomly collected from an apple orchard in Shaanxi Province was obtained. The developed method based on questionnaires should be significant for monitoring pesticide residues in Chinese apple orchards.

\section{Acknowledgements}

This work was supported by the National Key Research and Development Program of China (2016YFD0201200, 2016YFD0201203) and the Open Fund supported by the Key Laboratory for Environmental Factors Control of Agro-Product Quality Safety, Ministry of Agriculture.

\section{Conflict of Interest}

The authors declare no conflict of interest

\section{References}

1. CHEN Q. The Analysis of Influence Factors in Pesticides Use from Apple Growers in Shaanxi Province. Northwest Agriculture \& Forestry University, 2013.

2. SIMON S., LESUEUR-JANNOYER M., PLENET D., LAURI P.-E., LE BELLEC F. Methodology to design agroecological orchards: Learnings from on-station and on-farm experiences. European Journal of Agronomy, 82, 320, 2017.

3. HE M., JIA C.H., ZHAO E.C., CHEN L., YU P.Z., JING J.J., ZHENG Y.Q. Concentrations and dissipation 
of difenoconazole and fluxapyroxad residues in apples and soil, determined by ultrahigh-performance liquid chromatography electrospray ionization tandem mass spectrometry. Environmental Science and Pollution Research, 23 (6), 5618, 2016.

4. MORSELLI M., VITALE C.M., IPPOLITO A., VILLA S., GIACCHINI R., VIGHI M., DI GUARDO A. Predicting pesticide fate in small cultivated mountain watersheds using the DynAPlus model: Toward improved assessment of peak exposure. Science of the Total Environment, 615, 307, 2018.

5. MA L.P. Behavior for safe agro-products of apple farmer households: comparative analysisi on typical transaction model. Northwest agriculture and forestry university, 2017.

6. GUO C., LI J.Z., GUO B.Y., WANG H.L. Determination and Safety Evaluation of Difenoconazole Residues in Apples and Soils. Bulletin of Environmental Contamination and Toxicology, 85 (4), 427, 2010.

7. PAROLO M.E., SAVINI M.C., LOEWY R.M. Characterization of soil organic matter by FT-IR spectroscopy and its relationship with chlorpyrifos sorption. Journal of Environmental Management, 196, 316, 2017.

8. LI J., DONG F.S., CHENG Y.P., LIU X.G., XU J., LI Y.B., CHEN X., KONG Z.Q., ZHENG Y.Q. Simultaneous enantioselective determination of triazole fungicide difenoconazole and its main chiral metabolite in vegetables and soil by normal-phase high-performance liquid chromatography. Analytical and Bioanalytical Chemistry, 404 (6-7), 2017, 2012.

9. WANG W.M., SUN Q., LI Y.B., WEN G.Y., FAN J.Q., SONG W.G., ZHAO Z.H., DONG M.F. Simultaneous Determination of Fluoxastrobin and Tebuconazole in Cucumber and Soil Based on Solid-Phase Extraction and LC-MS/MS Method. Food Analytical Methods, 11 (3), 750, 2018.

10. WU S., ZHANG H., ZHENG K., MENG B., WANG F., CUI Y., ZENG S., ZHANG K., HU D. Simultaneous determination and method validation of difenoconazole, propiconazole and pyraclostrobin in pepper and soil by LC-MS/MS in field trial samples from three provinces, China. Biomedical Chromatography, 2017.

11. DONG B.Z., YANG Y.P., PANG N.N., HU J.Y. Residue dissipation and risk assessment of tebuconazole, thiophanatemethyl and its metabolite in table grape by liquid chromatography-tandem mass spectrometry. Food Chemistry, 260, 66, 2018.

12. SAHA S., MONDAL R., MUKHERJEE S., SARKAR M., KOLE R.K. Persistence of acetamiprid in paddy and soil under West Bengal agro-climatic conditions. Environmental Monitoring and Assessment, 189 (4), 150, 2017.

13. TIMOFEEVA I., SHISHOV A., KANASHINA D., DZEMA D., BULATOV A. On-line in-syringe sugaringout liquid-liquid extraction coupled with HPLC-MS/ MS for the determination of pesticides in fruit and berry juices. Talanta, 167, 761, 2017.

14. CHENG Z., DONG F., XU J., LIU X., WU X., CHEN Z., PAN X., GAN J., ZHENG Y. Simultaneous determination of organophosphorus pesticides in fruits and vegetables using atmospheric pressure gas chromatography quadrupole-time-of-flight mass spectrometry. Food Chemistry, 231, 365, 2017.

15. CHENG Z., DONG F., XU J., LIU X., WU X., CHEN Z., PAN X., ZHENG Y. Atmospheric pressure gas chromatography quadrupole-time-of-flight mass spectrometry for simultaneous determination of fifteen organochlorine pesticides in soil and water. Journal of Chromatography A, 1435, 115, 2016.

16. DALLEGRAVE A., PIZZOLATO T.M., BARRETO F., ELJARRAT E., BARCELO D. Methodology for trace analysis of 17 pyrethroids and chlorpyrifos in foodstuff by gas chromatography-tandem mass spectrometry. Analytical and Bioanalytical Chemistry, 408 (27), 7689, 2016.

17. NIE J.Y., LI Z.X., LIU C.D., FAN J.B., WANG C., GUO Y.Z., LEI S.R., LI H.F., XU G.F., YAN Z. Risk Assessment of Pesticide Residues in Apples. Scientia Agricultura Sinica, 47 (18), 3655, 2014.

18. SHI X., JI L.L., ZHU D.Q. Investigating roles of organic and inorganic soil components in sorption of polar and nonpolar aromatic compounds. Environmental Pollution, 158 (1), 319, 2010.

19. FIGUEROA-DIVA R.A., VASUDEVAN D., MACKAY A.A. Trends in soil sorption coefficients within common antimicrobial families. Chemosphere, 79 (8), 786, 2010.

20. LI L.Y., WANG Y.P., HAN M.Y., ZHANG L.S., MU Y. Physical and chemical properties of soil in apple orchards of Luochuan. Journal of Northwest A \& F University. Natural Science Edition, 44 (4), 185, 2016.

21. WANG L.H., TONG Y.N., LIU J. Assessment on current situation of soil organic matter of apple orchards in Weibei areas. Agricultural Research in the Arid Areas, 25 (6), 189, 2007.

22. LIU A.F., SHEN Z.S., TIAN Y., SHI R.G., LIU Y., ZHAO Z.S., XIAN M. Thin-layer chromatography coupled with high performance liquid chromatography for determining tetrabromobisphenol $\mathrm{A} / \mathrm{S}$ and their derivatives in soils. Journal of Chromatography A, 1526, 151, 2017.

23. LESUEUR C., GARTNER M., MENTLER A., FUERHACKER M. Comparison of four extraction methods for the analysis of 24 pesticides in soil samples with gas chromatography-mass spectrometry and liquid chromatography-ion trap-mass spectrometry. Talanta, $\mathbf{7 5}$ (1), 284, 2008.

24. GOMEZ-RAMOS M.M., FERRER C., MALATO O., AGUERA A., FERNANDEZ-ALBA A.R. Liquid chromatography-high-resolution mass spectrometry for pesticide residue analysis in fruit and vegetables: Screening and quantitative studies. Journal of Chromatography A, 1287, 24, 2013.

25. FU Y., YANG T., ZHAO J., ZHANG L., CHEN R., WU Y. Determination of eight pesticides in Lycium barbarum by LC-MS/MS and dietary risk assessment. Food Chemistry, 218, 192, 2017.

26. LIU N., DONG F.S., LIU X.G., XU J., LI Y.B., HAN Y.T., ZHU Y.L., CHENG Y.P., CHEN Z.L., TAO Y., ZHENG Y.Q. Effect of household canning on the distribution and reduction of thiophanate-methyl and its metabolite carbendazim residues in tomato. Food Control, 43, 115, 2014.

27. GRIMALT S., DEHOUCK P. Review of analytical methods for the determination of pesticide residues in grapes. J Chromatography A, 1433, 1, 2016.

28. FAN S., ZHAO P., YU C., PAN C., LI X. Simultaneous determination of 36 pesticide residues in spinach and cauliflower by LC-MS/MS using multi-walled carbon nanotubes-based dispersive solid-phase clean-up. Food Additives \& Contaminants: Part A: Chemistry, Analysis, Control, Exposure \& Risk Assessment, 31 (1), 73, 2014.

29. TIAN F.J., LIU X.G., XU J., DONG F.S., ZHENG Y.Q., HU M.F., WU Y.B. Simultaneous Determination of 
Phoxim, Chlorpyrifos, and Pyridaben Residues in Edible Mushrooms by High-Performance Liquid Chromatography Coupled to TandemMass Spectrometry. Food Analytical Methods, 9 (10), 2917, 2016.

30. CHEN X., XU J., LIU X., TAO Y., PAN X., ZHENG Y., DONG F. Simultaneous determination of trifloxystrobin and trifloxystrobin acid residue in rice and soil by a modified quick, easy, cheap, effective, rugged, and safe method using ultra high performance liquid chromatography with tandem mass spectrometry. Journal of Separation Science, 37 (13), 1640, 2014.

31. UTTURE S.C., BANERJEE K., KOLEKAR S.S., DASGUPTA S., OULKAR D.P., PATIL S.H., WAGH S.S., ADSULE P.G., ANUSE M.A. Food safety evaluation of buprofezin, dimethoate and imidacloprid residues in pomegranate. Food Chemistry, 131 (3), 787, 2012.

32. FERREIRA J.A., FERREIRA J.M.S., TALAMINI V., FACCO J.F., RIZZETTI T.M., PRESTES O.D., ADAIME M.B., ZANELLA R., BOTTOLI C.B.G. Determination of pesticides in coconut (Cocos nucifera Linn.) water and pulp using modified QuEChERS and LC-MS/MS. Food Chemistry, 213, 616, 2016.

33. SALIS S., TESTA C., RONCADA P., ARMORINI S., RUBATTU N., FERRARI A., MINIERO R., BRAMBILLA G. Occurrence of imidacloprid, carbendazim, and other biocides in Italian house dust: Potential relevance for intakes in children and pets. Journal of Environmental Science and Health Part B-Pesticides Food Contaminants and Agricultural Wastes, 52 (9), 699, 2017.

34. LIANG H.W., QIU J., LI L., LI W., ZHOU Z.Q., LIU F.M., QIU L.H. Stereoselective separation and determination of triadimefon and triadimenol in wheat, straw, and soil by liquid chromatography-tandem mass spectrometry. Journal of Separation Science, 35 (1), 166, 2012.

35. LIU T.F., ZHANG L., QIAN H., XIE X.Q., YANG D.F., DONG M.H. Simultaneous determination of chlorpyrifos and cypermethrin residues in soil by QuEChERS-GC/ muECD. Jiangsu Journal of Agricultural Sciences, 30 (6), 1495, 2014
36. ZHOU Q.F., MO R.F., YANG Y.X. Determination of pyridaben residues in citrus fruits and soil using gas chromatography. Journal of Southern Argiculture, 43 (1), 42, 2012.

37. MAHAPATRA B., ADAK T., PATIL N.K.B., PANDI G.G.P., GOWDA G.B., YADAV M.K., MOHAPATRA S.D., RATH P.C., MUNDA S., JENA M. Effect of Abiotic Factors on Degradation of Imidacloprid. Bulletin of Environmental Contamination and Toxicology, 99 (4), 475, 2017.

38. DORUCHOWSKI G., SWIECHOWSKI W., MASNY S., MACIESIAK A., TARTANUS M., BRYK H., HOLOWNICKI R. Low-drift nozzles vs. standard nozzles for pesticide application in the biological efficacy trials of pesticides in apple pest and disease control. Science of the Total Environment, 575, 1239, 2017.

39. TONG Z., WU Y.C., LIU Q.Q., SHI Y.H., ZHOU L.J., LIU Z.Y., YU L.S., CAO H.Q. Multi-Residue Analysis of Pesticide Residues in Crude Pollens by UPLC-MS/MS. Molecules, 21 (12), 2016.

40. ALAMGIR ZAMAN CHOWDHURY M., FAKHRUDDIN A.N.M., NAZRUL ISLAM M., MONIRUZZAMAN M., GAN S.H., KHORSHED ALAM M. Detection of the residues of nineteen pesticides in fresh vegetable samples using gas chromatography-mass spectrometry. Food Control, 34 (2), 457, 2013.

41. MAHAPATRA B., ADAK T., PATIL N.K.B., PANDI G.P.G., GOWDA G.B., JAMBHULKAR N.N., YADAV M.K., PANNEERSELVAM P., KUMAR U., MUNDA S., JENA M. Imidacloprid application changes microbial dynamics and enzymes in rice soil. Ecotoxicology and Environmental Safety, 144, 123, 2017.

42. HERRERA LOPEZ S., LOZANO A., SOSA A., HERNANDO M.D., FERNANDEZ-ALBA A.R. Screening of pesticide residues in honeybee wax comb by LC-ESI-MS/MS. A pilot study. Chemosphere, 163, 44, 2016. 